\title{
Printed single-layer ACPW stepped-feed monopole antenna for LTE/WLAN band applications
}

\author{
Su-Mei Shen ${ }^{1}$, I-Fong Chen ${ }^{2 a)}$, Chia-Mei Peng ${ }^{2}$, \\ and Ding-Bing Lin $^{1}$ \\ ${ }^{1}$ Department of Electronic Engineering, National Taipei University of Technology, \\ 1, Sec. 3, Zhongxiao E. Rd., Taipei 10608 Taiwan, R.O.C. \\ 2 Department of Electronic Engineering, Jinwen University of Science and \\ Technology, No. 99, An-chung Road, Hsin-tien District, 23154 New Taipei City,
}

Taiwan, R.O.C.

a)ex0206@just.edu.tw

Abstract: The ability of a printed single-layer monopole antenna, which is composed of diamond-fed slotted top-loading, asymmetric co-planar waveguide (ACPW) and stepped-feeding structure, to operate at three wide frequency bands $(698 \sim 960 \mathrm{MHz}, 1710 \sim 2690 \mathrm{MHz}$ and $3400 \sim 3800 \mathrm{MHz})$ to cover WLAN and LTE operation has been demonstrated in this article. A prototype of the proposed antenna with $106 \mathrm{~mm}$ in length, $0.8 \mathrm{~mm}$ in thickness and $15 \mathrm{~mm}$ in width is fabricated and experimentally investigated. The experimental results indicate that the VSWR 2.5:1 bandwidths achieved were $71.43 \%, 48.16 \%$ and $13.89 \%$ at $700 \mathrm{MHz}, 2450 \mathrm{MHz}$ and $3600 \mathrm{MHz}$, respectively. There is good agreement between the simulated and measured results.

Keywords: monopole antenna, slotted top-loading, asymmetric co-planar waveguide, WLAN, LTE

Classification: Antennas and Propagation

\section{References}

[1] J. D. Kraus and R. J. Marhefka, Antennas, McGraw-Hill, New York, 2002.

[2] L. Lizzi and A. Massa, "Dual-band printed fractal monopole antenna for LTE applications," IEEE Antennas Wireless Propag. Lett., vol. 10, pp. 760-763, July 2011. DOI:10.1109/LAWP.2011.2163051

[3] J. Ma, Z. Y. Ying, L. G. Jing, and H. H. You, "Miniature printed octaband monopole antenna for mobile phones," IEEE Antennas Wireless Propag. Lett., vol. 9, pp. 1033-1036, Oct. 2010. DOI:10.1109/LAWP.2010.2088374

[4] K. Chung, S. Hong, and J. Choi, "Ultrawide-band printed monopole antenna with band-notch filter," IET Microw. Antennas Propag., vol. 1, no. 2, pp. 518522, Apr. 2007. DOI:10.1049/iet-map:20050356

[5] T. G. Ma and S. K. Jeng, "Planar miniature tapered-slot-fed annular slot for ultra wide-band radios," IEEE Antennas Propag., vol. 53, no. 3, pp. 1194-1202, March 2005. DOI:10.1109/TAP.2004.842648 
[6] A. Cabedo, J. Anguera, C. Picher, M. Ribó, and C. Puente, "Multi-band handset antenna combining a PIFA, slots, and ground plane modes," IEEE Trans. Antennas Propag., vol. 57, no. 9, pp. 2526-2533, Sep. 2009. DOI:10.1109/ TAP.2009.2027039

[7] C.-M. Peng, I-F. Chen, and C.-H. Liou, "Multiband printed asymmetric dipole antenna for LTE/WLAN applications,” Int. J. Antennas Propag., vol. 2013, 704847, Dec. 2013. DOI:10.1155/2013/704847

\section{Introduction}

Recent rapidly technical advances in wireless communications stimulate the developments of different standards such as the IEEE 802.11 wireless local area network (WLAN) in the $2.4 \mathrm{GHz}(2400-2500 \mathrm{MHz})$ band, and the pre-4G technologies such as long term evolution (LTE) in the $700 \mathrm{MHz}(698-960 \mathrm{MHz})$ band, $1800 \mathrm{MHz}(1710-2170 \mathrm{MHz})$ band, $2.4 \mathrm{GHz}(2300-2700 \mathrm{MHz})$ band and $3.6 \mathrm{GHz}$ $(3400-3800 \mathrm{MHz})$ band. Therefore, the antenna is required to operate at different frequency bands or broadband in WLAN and LTE system. Some of the antennas desired features include multi-band, broad bandwidth, simple impedance matching to the feed line and low profile. A variety of printed monopole antennas for covering multi-bands have been reported in the published articles [1, 2, 3, 4, 5], those types of printed monopole antenna designs occupy a relatively larger space, they are difficult to meet the size-limited of the external radome cover of antenna. In this article, we present a single-layer multiband broadband printed ACPW stepped-feed monopole antenna for LTE/WLAN external antenna applications. The lengths of monopole (signal-trace) and co-planar waveguide (ground-trace) are designed to response two different resonant frequencies, respectively. It is beneficial to enhance antenna performance by let the length of ground-trace is larger than the signal-trace [6]. In other words, the length of signal-trace is designed for upperoperating band, and the ground-trace is designed for lower-operating band. The proposed antenna is consisted of diamond-fed slotted top-loading, asymmetric coplanar waveguide (ACPW) and stepped-feeding structure, which was developed by modifying the structure of printed asymmetric dipole antenna [7]. Details of the design considerations of the proposed antenna and the experimental results of constructed prototypes are presented and discussed.

\section{Antenna structure and design}

As for the specification requirement of wireless products, the multiband antenna is required to enable operations at the two WLAN and the LTE bands, whose bandwidths and list of the corresponding bands are detailed in Fig. 1(a). The operating frequency range is divided into three bands: $700 \mathrm{MHz}$ band $(698-960$ $\mathrm{MHz}), 2 \mathrm{GHz}$ band $(1710-2700 \mathrm{MHz})$ and $3.6 \mathrm{GHz}$ band $(3400-3800 \mathrm{MHz})$; in which the $700 \mathrm{MHz}$ band was denoted as lower-operating band, and $2 \mathrm{GHz}$ and $3.6 \mathrm{GHz}$ bands were denoted as upper-operating band. Accordingly, a good impedance matching in those operating ranges is needed. Such a requirement has been conveniently expressed in terms of VSWR by imposing a suitable threshold 
on the magnitude values of the VSWR $\leq 2.5$. Fig. 1(b) shows the original geometry ACPW stepped-feeding monopole antenna for multiband applications. The length of signal-arm and ground-arm are related to the upper- and lowerfrequency, respectively. The difference height of ACPW-fed structure is h. The presented antenna structure is composed of an upper-element section of length S1, and the lower-element section of length S2, and the ground-trace section of electrical-length S3. These sections are all printed on a $0.8 \mathrm{~mm}$-thick FR4 glass epoxy substrate (the relative permittivity is 4.3 , and the loss tangent is 0.022 ) at the same layer, the profile and side view of the proposed antenna are shown in the Fig. 1(c). The resonant mode of total shape $(\mathrm{S} 1+\mathrm{S} 2)$ is designed to occur at $2450 \mathrm{MHz}$, the lower-element (S2) is designed to resonate at $3600 \mathrm{MHz}$, and the ground-trace (S3) is designed to resonate at $700 \mathrm{MHz}$. The length of radiating elements can be determined from about quarter-wave length at the resonant frequencies. Note that the widths of these sections are not identical. By selecting appropriate dimensions (S1, S2, S3) of the antenna structure, good impedance matching of the printed asymmetric dipole can be obtained across an extended bandwidth. The corresponding characteristics of resonant frequency, input impedance and bandwidth are a function of the geometrical parameters of the slotted top-loading and ACPW stepped feeding structure, the configuration and dimensions of the proposed antenna are shown in the Fig. 1(d). When the dimension of the diamond-fed slotted top-loading is varied, the impedance bandwidth and resonant frequency will change in the $2450 \mathrm{MHz}$ band. An ACPW stepped-feeding structure excites the end of S2-segment as shown in Fig. 1(c). The impedance matching at $2 \mathrm{GHz}$ and $3.6 \mathrm{GHz}$ bands can be tuned by this structure, which was found to be effective in obtaining a wider impedance bandwidth in the antenna's upper-operating band. In addition, it should be noted that the ground-trace length (S3) and configuration could also affect the resonant frequency and operating bandwidth of $700 \mathrm{MHz}$ band; when the printed ground-trace was chiseled slots, the operating bandwidth will increase. The bended ground-trace (ACPW structure) is designed for the lower-operating band, which is also act as a sleeve balun for the upperoperating band, a complete radiation pattern-shape can be obtained. The impedance matching at $700 \mathrm{MHz}, 2 \mathrm{GHz}$ and $3.6 \mathrm{GHz}$ bands can be tuned by the steppedfeeding of signal-trace, which was found to be effective in securing triple band. The access point (AP) is the intended platform of antenna integration. The proposed antenna's size is based on the size of paddle radome cover, as shown in Fig. 1(e).

\begin{tabular}{|c|c|c|}
\hline \multicolumn{3}{|c|}{ LTE } \\
\hline & Allocated Bands & Frequency Range [MHz] \\
\hline \multirow{3}{*}{ FDD } & $\begin{array}{c}\# 5, \# 6, \# 8, \# 12, \# 13, \# 14, \# 17, \\
\# 18, \# 19, \# 20\end{array}$ & $698-960$ \\
\hline & $\# 1, \# 2, \# 3, \# 4, \# 9, \# 10, \# 30$ & $1900-2620$ \\
\hline & $\# 22$ & $3410-3590$ \\
\hline \multirow[t]{2}{*}{ TDD } & $\begin{array}{c}\# 33, \# 34, \# 35, \# 36, \# 37, \# 38, \\
\# 39, \# 40, \# 41\end{array}$ & $1850-2690$ \\
\hline & $\# 42, \# 43$ & $3400-3800$ \\
\hline \multicolumn{3}{|c|}{ WLAN } \\
\hline & $2.4 \mathrm{GHz}$ & $2400-2500$ \\
\hline
\end{tabular}

(a) Considered WLAN and LTE bands. 


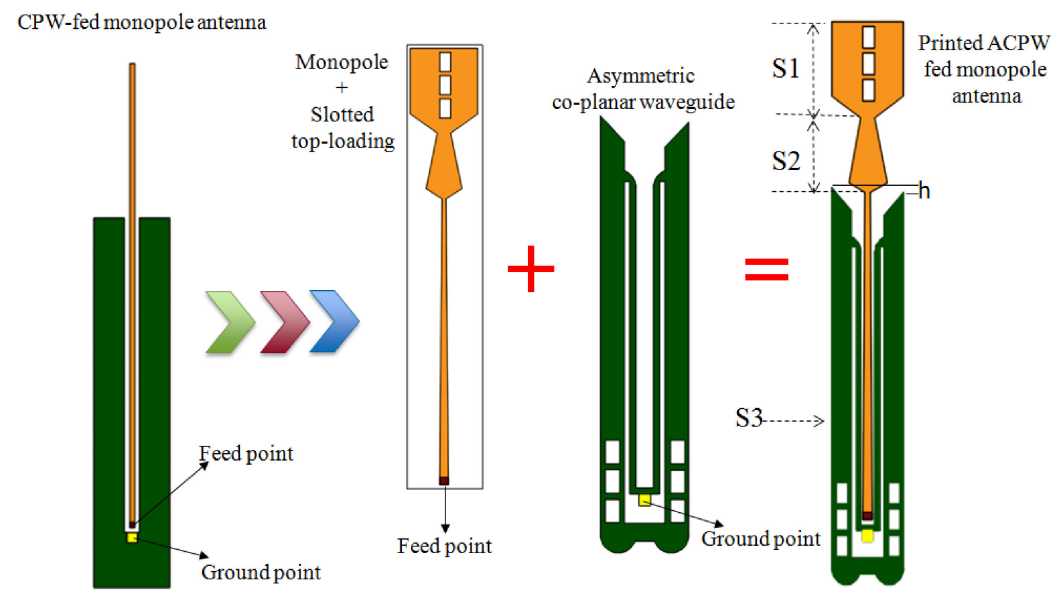

(b) The original geometry structure of the proposed antenna.
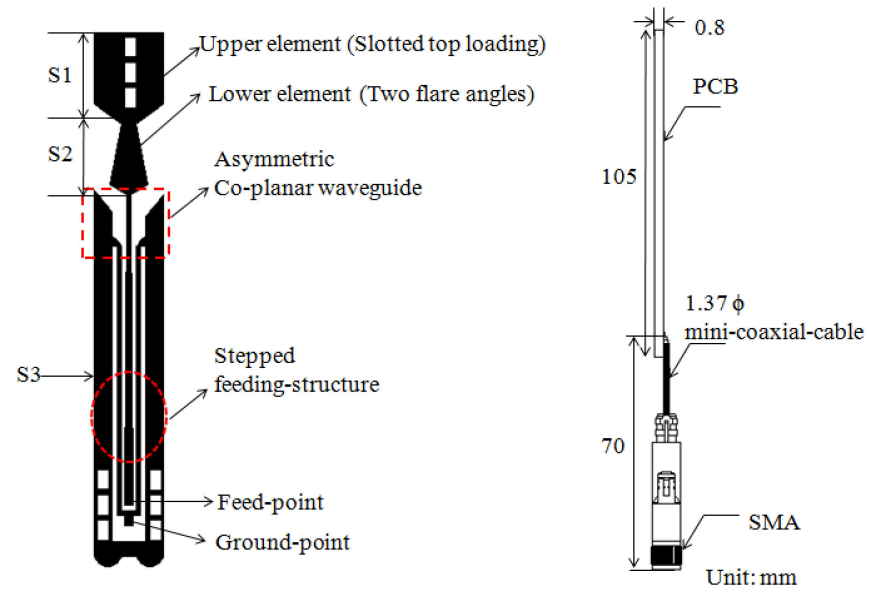

(c) Profile and side view of the proposed antenna.

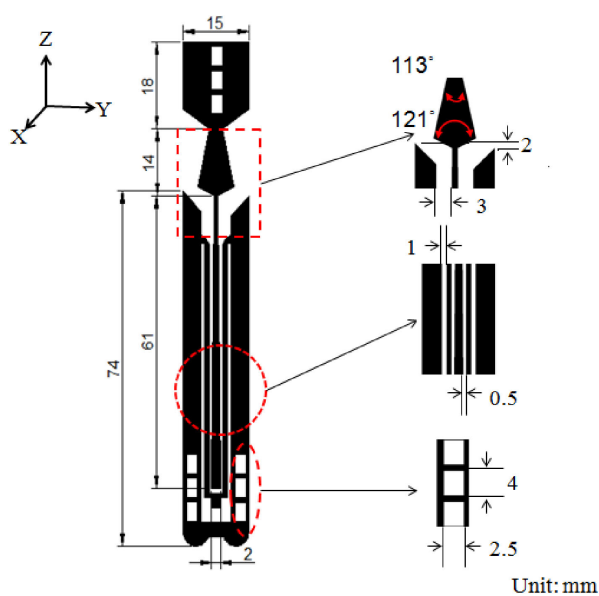

(d) Configuration and dimensions of the proposed antenna.

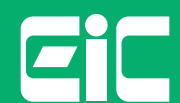

๑) IEICE 2016

DOI: $10.1587 /$ comex.2016XBL0021

Received January 22, 2016

Accepted March 14, 2016

Publicized March 30, 2016

Copyedited June 1, 2016 


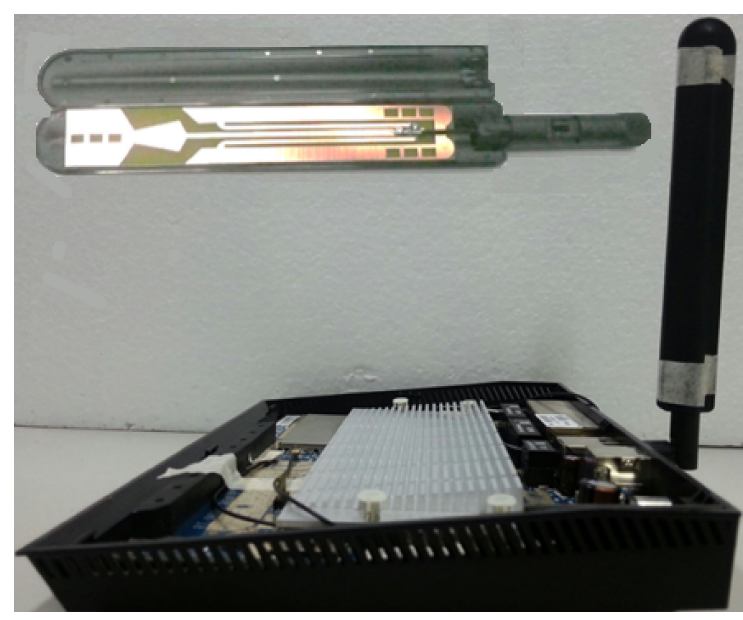

(e) The paddle radome cover of antenna

Fig. 1. The corresponding bands and structure of the proposed antenna.

\section{Experimental results and discussion}

In the experiment, the feeding-point and ground-point are connected to a $1.13 \varnothing$ $3 \mathrm{~cm}$ mini-coaxial cable with $50 \Omega$ SMA connector. By utilizing the above-mentioned design procedure, a wide band antenna was constructed to operate at the range of WLAN and LTE system $(698 \sim 960 \mathrm{MHz}, 1710 \sim 2690 \mathrm{MHz}$ and 3400 $3800 \mathrm{MHz}$ ). Fig. 2(a) shows the simulated (by Ansoft HFSS) and measured VSWR plot of the wideband antenna as a result of this geometry. The measured VSWR $\leq 2.5$ bandwidths are $71.43 \%$ at $700 \mathrm{MHz}, 48.16 \%$ at $2450 \mathrm{MHz}$ and $13.89 \%$ at $3600 \mathrm{MHz}$. There is good agreement between the measured and simulated results. Fig. 2(b) presents the simulated current distribution of the proposed antenna at $700 \mathrm{MHz}, 2450 \mathrm{MHz}$ and $3600 \mathrm{MHz}$ which are corresponding to the resonant length of the $\mathrm{S} 3, \mathrm{~S} 1+\mathrm{S} 2$ and $\mathrm{S} 2$, respectively; simulation results are shown to verify the validity of theoretical work. The effect of varying the top-loading, feeding structure and the ground-trace structure on the antenna performance has been studied. The configuration of varied antenna structure is shown in the Fig. 3(a), and the measured VSWR plot of the corresponding structure is shown in the Fig. 3(b). From Fig. 3(b), it is obviously that the tuning of the $2450 \mathrm{MHz}$ band was acquired by adjusting the fed-structure of slotted top-loading to produce the required frequency response characteristic. The diamond-fed $\left(\theta_{1}: 121^{\circ}, \theta_{2}: 113^{\circ}\right)$ slotted top-loading width increase will lead to an increase impedance bandwidth and a decrease resonant frequency in the $2450 \mathrm{MHz}$ band, which is shown in the Fig. 3(b). In addition, to let the co-planar waveguide feeding structure to be an asymmetric structure (the optimal difference height (h) is $2 \mathrm{~mm}$ ), it was observed that the resonant frequency and impedance bandwidth will increase in $2450 \mathrm{MHz}$ band, nevertheless, the effect in $700 \mathrm{MHz}$ band is very small. Furthermore, when the printed ground-trace was chiseled slots, the operating bandwidth will increase. The ground-trace length (S3) and configuration could also affect the resonant frequency and operating bandwidth of the $700 \mathrm{MHz}$ band. The impedance matching was also achieved by optimizing the stepped-feeding trace. 


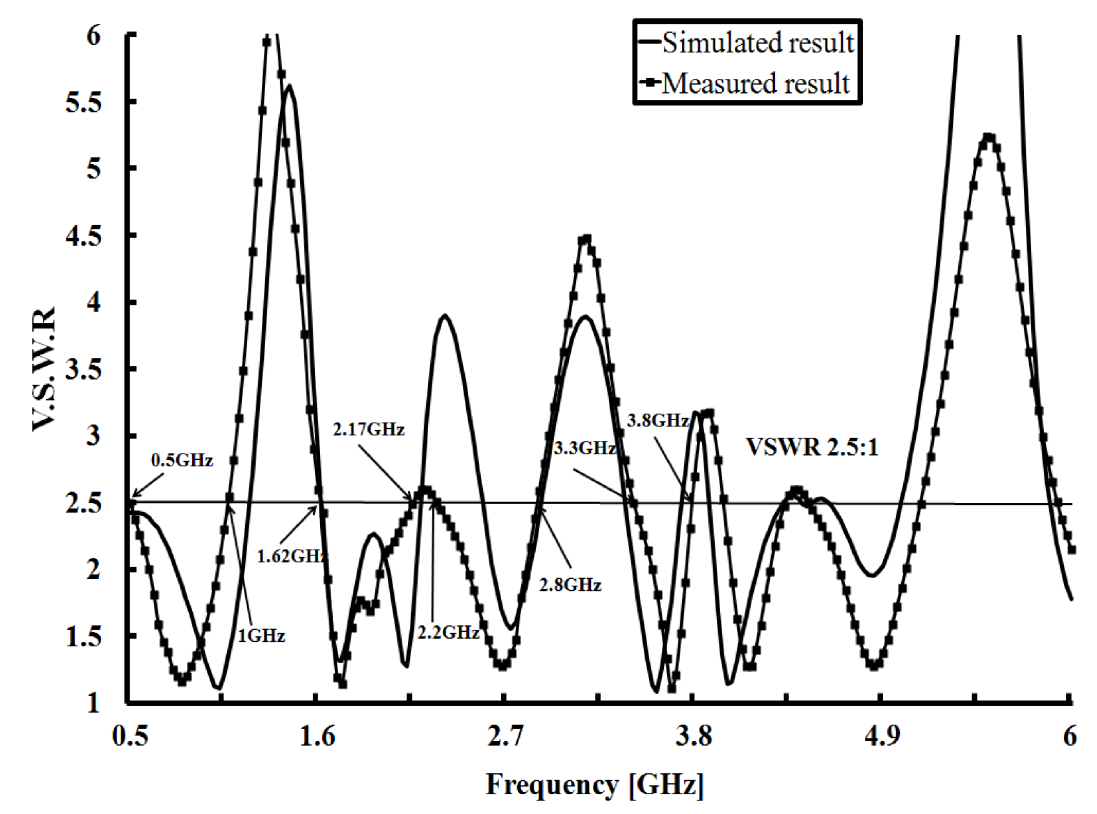

(a) Measured and simulated VSWR against frequency of the proposed antenna.

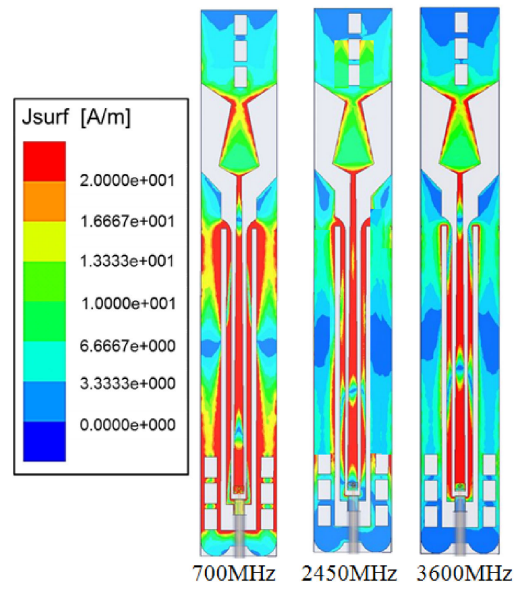

(b) The simulated current distribution against frequency of the proposed antenna.

Fig. 2. Broadband triple-band operating by the design of ACPW-fed and slotted top-loading structure.

The measured radiation patterns for free space at $700 \mathrm{MHz}, 2450 \mathrm{MHz}$ and $3600 \mathrm{MHz}$ in the xy-plane and zx-plane are shown in Fig. 3(d), respectively. Fig. 3(e) shows the measured antenna gains and 3D pattern efficiency within the operating bands of the proposed antenna. Stable radiation patterns are observed. The total 3D pattern efficiency is defined as (Gain/Directivity) $\times 100 \%$, which was done by using pattern integration employing the ETS-Lindgren anechoic chamber. Acceptable radiation characteristic for the practical applications is obtained for the proposed antenna. The omni-directional feature of the proposed antenna can also be observed from the xy-plane, where the gain variation between maximum and minimum levels is less than $3 \mathrm{~dB}$. The ground-trace is also act as a sleeve balun, a close to complete radiation shape (there is a few variations in the radiation pattern-shapes) was obtained. 


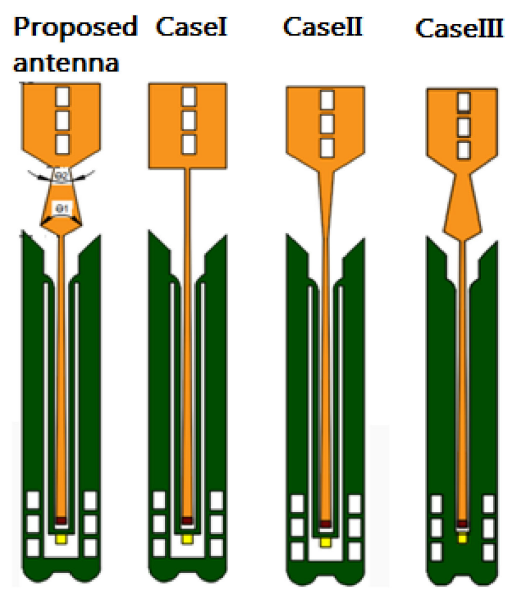

(a). The configuration of varying antenna structure.

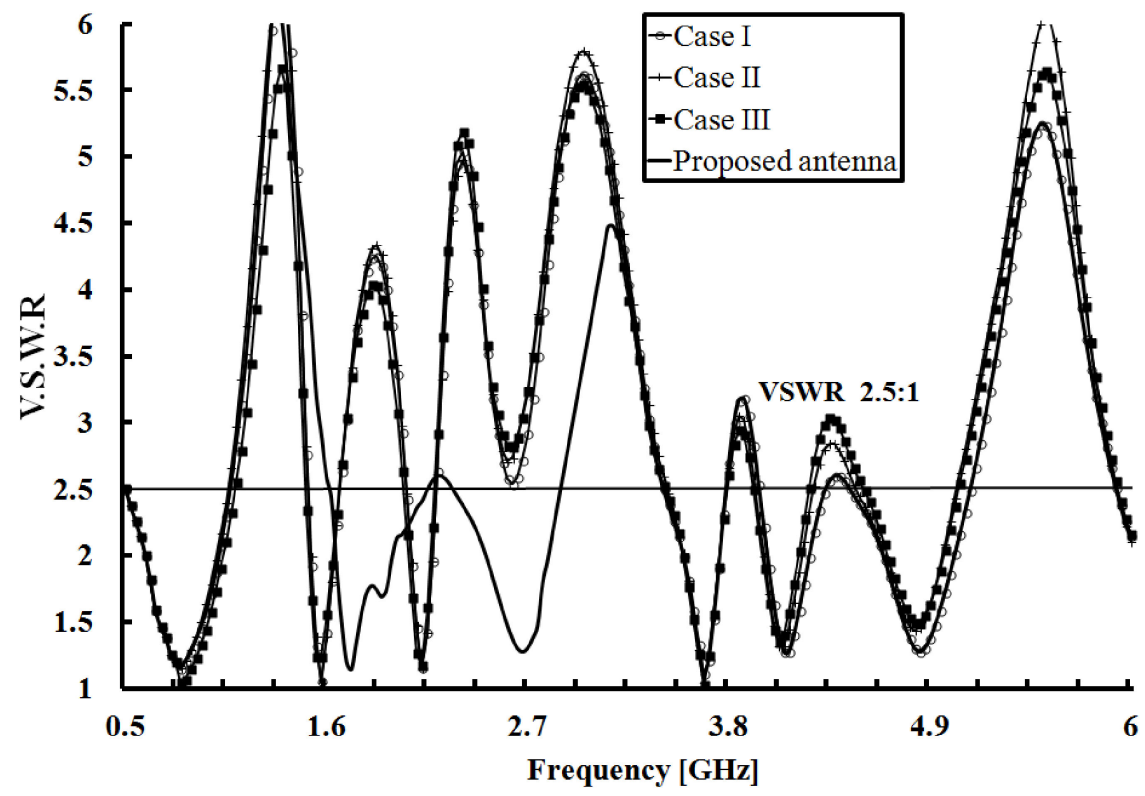

(b). Measured VSWR against frequency of the corresponding antenna structure. 


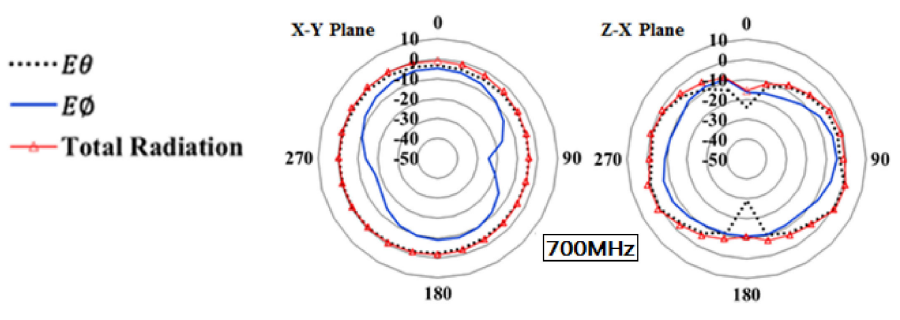

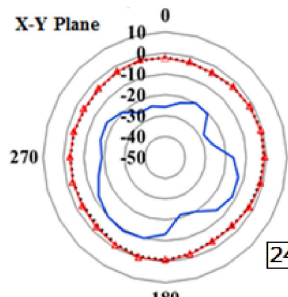

180

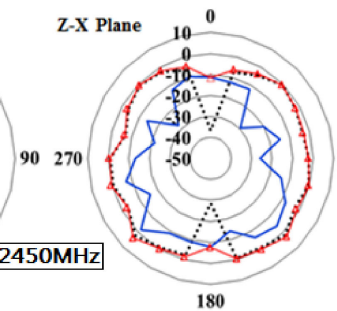

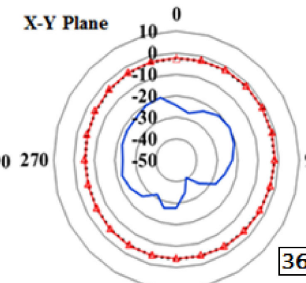

180

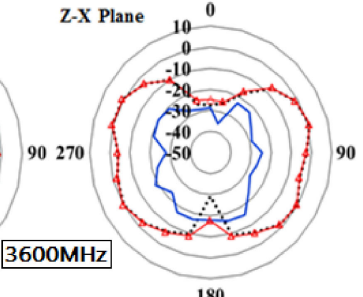

(c). Measured radiation patterns for the proposed antenna.

\begin{tabular}{|c|c|c|c|}
\hline \multirow{2}{*}{ Fain (dBi) } & xy-plane & Zx-plane & \multirow{2}{*}{ Efficiency (\%) } \\
\cline { 2 - 3 } & Max. Gain & Max. Gain & \\
\hline 700 & -0.16 & 1.48 & 66.92 \\
\hline 960 & -0.44 & 2.45 & 57.04 \\
\hline 1710 & 1.14 & 2.13 & 61.26 \\
\hline 2170 & 2.09 & 1.99 & 73.90 \\
\hline 2450 & 2.48 & 2.01 & 75.36 \\
\hline 2700 & -0.27 & 3.54 & 76.52 \\
\hline 3000 & -1.49 & 0.25 & 74.38 \\
\hline 3300 & -1.5 & 0.87 & 66.02 \\
\hline 3600 & 0.24 & 2.23 & 75.71 \\
\hline
\end{tabular}

(d). The measured antenna gains and efficiencies within the operating bandwidth of the proposed antenna. The symbol's meaning: "Max.: maximum; Min.: minimum".

Fig. 3. The radiation features of the proposed antenna.

\section{Conclusion}

In this article, a multi-band broadband printed single-layer ACPW stepped-feed monopole antenna suitable for WLAN and LTE applications has been proposed. The antenna is characterized by a suitable impedance matching over the presented operating band. The performances of the synthesized antenna have been numerically and experimentally verified. The proposed antenna can be easily fabricated and modified to various AP and Router as a compact external antenna.

\section{Acknowledgments}

This work was supported by National Science Council, R.O.C., under the Contract MOST 104-2221-E-228-001. The authors also appreciate the reviewer's comments to improve the quality of this paper. 